Wafaa k Abid

BDS, MSc (Lect)

\section{Post- surgical outcomes and prognosis of intentionally replanted lower post- erior teeth}

Department of Oral and Maxillofacial Surgery

College of Dentistry, University of Mosul

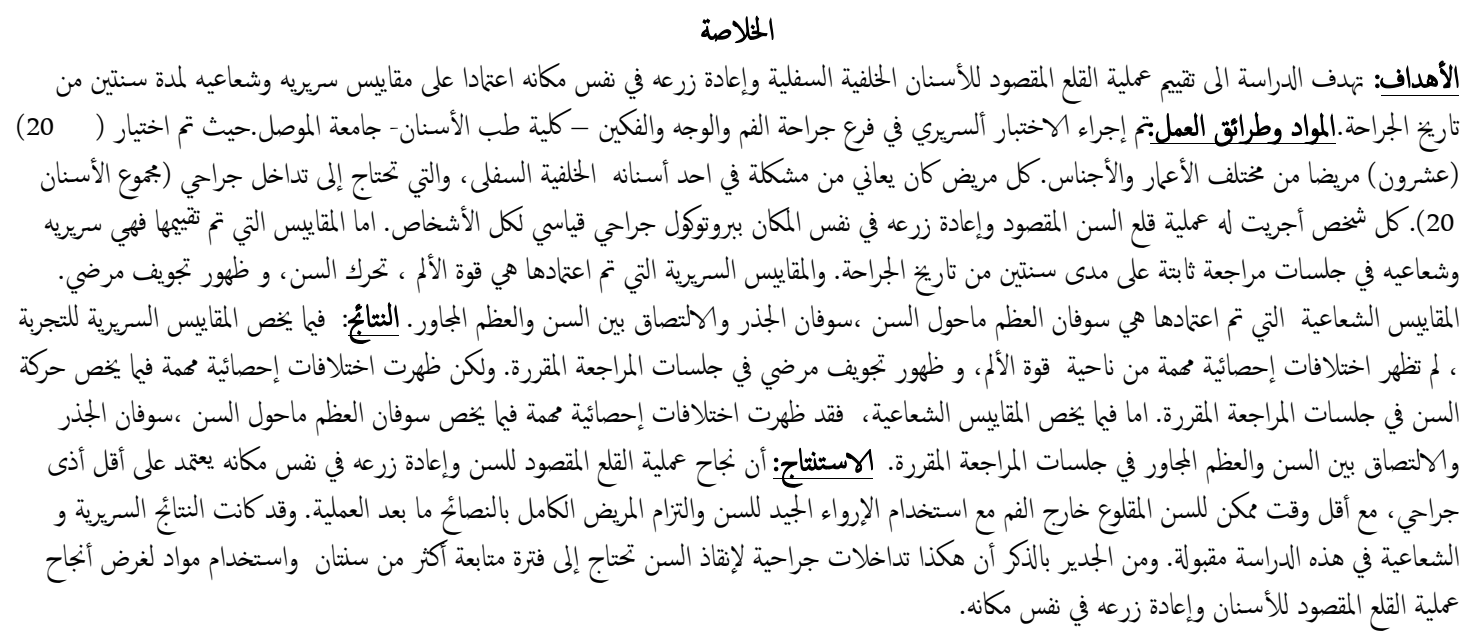

ABSTRACT

Aims: To evaluate intentional replantation based on clinical and radiographic assessment criteria over a two year period. Materials and Methods: The clinical trial was conducted at the Department of Oral and Maxillofacial Surgery/ College of Dentistry/ Mosul University. Twenty lower posterior teeth in twenty patients of different ages and genders were enrolled in the trial. Each patient was subjected to a standard surgical protocol for intentional replantation. The criteria evaluated were both clinical and radiographical on scheduled visits for two years for each patient. Clinical criteria included pain level, tooth mobility and sinus formation. Radiographical criteria were periapical radiolucency ,root resorption and ankylosis. Results: In regard to clinical criteria, no significant statistical difference was disclosed for pain score levels and sinus formation at the scheduled visits. However, significant difference was recorded for tooth mobility at different interval visits. For radiographic criteria, a significant difference for periapical radiolucency, root resorption and ankylosis was recorded at interval visits. Conclusion: The success of intentional replantation is likely dependent upon a minimally traumatic extraction, short extra-oral time with copious irrigation and meticulous instrumentation as well as carefully controlled postoperative patient compliance. The clinical and radiographic results of cases in the current trial were satisfactory. Further study on a much more post-operative period( more than two years) and the use of materials to improve the success of intentional replantation is encouraged.

Key Words: Intentional replantation, oral surgery,surgical endodontics.

Abid WK. Post- surgical outcomes and prognosis of intentionally replanted lower posterior teeth. Al-Rafidain Dent J. 2010; 10(2)332-340:.

Received: $14 / 6 / 2009$

Sent to Referees: $21 / 6 / 2009$

Accepted for Publication: 22/7/2009

\section{INTRODUCTION}

The central goal of dentistry is to maintain the integrity of the natural dentition which is essential for full function and natural esthetics ${ }^{(1)}$ In spite the fact that non-surgical endodontic procedures have a high success rate, failures do occur. ${ }^{(2,3)}$ These can be managed by root can- al re-treatment or surgical endodontic intervention. ${ }^{(4)}$ Intentional replantation (IR) is an accepted procedure in which a tooth is extracted and treated outside the oral cavity, then reinserted into its socket to correct an obvious radiographic or clinical failure. ${ }^{(5)}$ John Hunter recommended the replantation procedure in 1778 when the 
crown was partially destroyed by caries ${ }^{(6)}$ Intentional replantation is recommended as the treatment of choice in the following instances $^{(6,7)}$ :

1. When conventional root canal therapy and/or apical surgery treatment have failed

2. Accessibility problems: Periradicular surgery on mandibular molars is difficult because of dense buccal bone (external oblique ridge) and limited access.

3. Anatomic limitations: Proximity of the treated root apex to nerves such as the inferior alveolar or mental nerve or to anatomical structures such as the maxillary sinus can present problems with periradicular surgery.

4. When patients object to surgery because of many causes (time consuming or costly....ect).

5. When surgery would create a periodontal pocket as a result of extensive bone removal.

6. Persistent chronic pain: Sometimes, Intentional replantation is an option as a diagnostic tool when all former treatments fail to alleviate chronic pain. It also permits evaluation of unsuspected pathosis such as resorption or fractures.

7. Accidental exarticulation presuming the tooth has no periodontal defects.

However, IR is contraindicated in the following; ${ }^{(6,7)}$

1. Flared or curved roots which may fracture during extraction, thus hampering any attempt to replant the tooth.

2. Periodontal involvement: A healthy periodontium is essential for long term success.

3. Broken teeth: Vertically fractured or non restorable teeth.

The critical event in any reimplantation following avulsion or extraction of a tooth is the preservation of cellular vitality in the periodontal ligament under aseptic conditions. Regeneration of the periodontal ligament is vital to the survival of the tooth and an ever increasing body of evidence has demonstrated that replantation delayed beyond 5 minutes is associated with a decreased likelihood of periodontal ligament regeneration. ${ }^{(8)}$

The present clinical evaluation undertaken aimed to evaluate intentional replantation based on certain clinical and radiographic parameters over a period of two years post-operatively.

\section{MATERIALS AND METHODS}

The clinical trial was conducted at the Department of Oral and Maxillofacial surgery / Dental College / Mosul University. The sample enrolled in the clinical evaluation included 20 subjects of both genders (12 females and 8 males) with ages ranging between 18-45years. Inclusion criteria included:

1.Medically fit patients as certain systemic problems interfere with normal healing mechanisms.

2.Non-smoking patient as it interferes with normal physiological healing.

3.Lower first or second premolar and first molar teeth with clinical and radiographical evidence of periapical radiolucency (abcess, granuloma, cyst).

Before the procedure was to be performed, each patient was informed of its steps and the possibility of failure in the future and only after his or her approval the surgery was carried out. If any signs of acute inflammation were present at the time of surgery, the operation was delayed until signs and symptoms have subsided and relieved by pulp extirpation, incision and drainage with adequate antibiotic prescription. For the purpose of reducing extra-alveolar time of tooth which is a critical criterion to the success of intentional replantation ,removal of caries, old fillings and root canal treatment with pulp extirpation, mechanico-chemical debridement and placement of gutta percha root canal filling for each tooth was performed before surgery.

The surgery is described in the following steps:

1.Each patient was requested to rinse his or her mouth with $15 \mathrm{ml}$ of chlorhexidine mouth wash $0.12 \%$ for two minutes (Biofresh - K - Chlorhexidine 0.12\% Antiseptic Mouth Wash-Made in Syria) to reduce bacterial count during and after surgery.

2. All teeth were extracted under local anesthesia using 2\% xylestesin (lidocaine) with $0.015 \mathrm{mg} / \mathrm{ml}$ epinephrine, the amount of local anesthesia was 1 cartridge of $2 \mathrm{ml}$ per tooth and the regional nerve block technique (inferior alveolar nerve block) was performed with buccal infiltration technique in the buccal sulcus opposite to 
each tooth.

3. The attached gingiva and adjacent interdental papillae were separated from the tooth with a no.12 scalpel blade mounted on a no. 3 Bard Parker scalpel handle.

4. Extraction was done with care using minimal force. The use of elevators were contraindicated because of the potential damage to the periodontal ligament. The beaks of forceps were placed on the crown and were not to reach the cemento-enamel junction to avoid violating the integrity of the peridontium using apical closing force with rotational force then pull the tooth for premolar teeth and using mild buccolingual movement and a figure of eight maneuver for molar teeth.

5. Following extraction, touching the alveolar socket was avoided to maintain the integrity of the bony part of the periodontal ligament. Only if necessary, the apical part of socket was to be curetted gently to remove any pathosis. This should only take a few seconds.

6. With the tooth held between the index finger and thumb (from crown portion) of the non-operating hand and the root portion kept constantly soaked with physiological normal saline $0.9 \%$ ( Nacl-Made in Iraq) by squirting from a10ml disposable syringe, $2-3 \mathrm{~mm}$ of the apex was resected using a small head round diamond bur mounted on a high speed turbine under copious distal water irrigation. The resected end of tooth is flattened and a small class I cavity of $2 \mathrm{~mm}$ depth and encompassing the width of the canal was prepared with a small sized (no. 1 or 2) round bur. The apex was gently dried and a small amount of zinc-free amalgam with high cupper $(\mathrm{Cu})$ ( SDI - one spill - Made in Australia) mounted in an amalgam carrier was placed over the cavity and gently condensed and burnished with a small head end of a burnisher.

7. Before the tooth was to be replaced in the socket, the walls of socket were gently flushed with normal saline to remove the blood clot. In addition, the tooth was irrigated with saline to remove any residual cotton fibers and debris from root end filling material.

8. The tooth was gently placed back into its socket. This allows for a slow escape of blood between the reimplanted tooth and socket.

9. Slight pressure was applied to the buccal and lingual cortical plates to ensure adaptation. The time was calculated from the beginning of extraction to complete insertion of the tooth in its socket ranged between (2-3)minutes.

10. The patient was requested to carefully bite on his teeth and the occlusion was checked. The tooth should be free from occlusion.

11. Tooth stability was reinforced with $0 / 3$ black silk suture using a horizontal mattress technique in the interproximal spaces. They were removed 10 days later.

12. Follow up visits were scheduled for 2 years ( first week, second week, first month, second month ,six month, first year and second year post operatively.

13. Follow up criteria were based on clinical and radiographical observations at each visit and as follows:

- Pain level based on the visual analogue scale (VAS) ${ }^{(9)}$ as no pain, mild pain, moderate pain, severe pain.

- Mobility of replanted tooth.

- Presence or absence of sinus

- Periapical radiolucency

- Root resorption

- Bone ankylosis

In regard to the second criterion, tooth mobility was recorded according to the following classification ${ }^{(10)}$ :

1. Movability of the crown of the tooth 0.2 $1 \mathrm{~mm}$ in horizontal direction(recorded as degree I mobility).

2. Movability of the crown of the tooth exceeding $1 \mathrm{~mm}$ in horizontal direction (recorded as degree II mobility).

3. Movability of the crown of the tooth in both horizontal and vertical direction (recorded as degree III mobility).

The statistical analysis of data were conducted using SPSS program for windows version 11.5.The analysis used was Friedman Test for variables ( pain, mobility , presence or absence of sinus, periapical radiolucency, root resorption and ankylosis).Differences were considered significant when $\mathrm{p}$ values $\geq 0.001$.

\section{RESULTS}

Pain score levels from the first week postoperatively till the second year 
interval as scheduled is shown in Table(1). The great majority of subjects $(90 \%$ $100 \%)$ reported no pain during the entire follow up period. Mild pain score levels were recorded only in two identical cases (lower right first molars) during the first week, second week and second year postoperative intervals. No significant difference was disclosed between pain score levels and scheduled visits ( Chi square $=8.471$, d.f. $=6, p=0.206$ ).

Table (1): Frequency and percentage of pain score levels at scheduled visits.

\begin{tabular}{ccccccccc}
\hline Pain & $\begin{array}{c}\text { Frequency, Per- } \\
\text { centage }\end{array}$ & $\begin{array}{c}\mathbf{1}^{\text {st }} \\
\text { week }\end{array}$ & $\begin{array}{c}\mathbf{2}^{\text {nd }} \\
\text { week }\end{array}$ & $\begin{array}{c}\mathbf{1}^{\text {st }} \\
\text { month }\end{array}$ & $\begin{array}{c}\mathbf{2}^{\text {nd }} \\
\text { month }\end{array}$ & $\begin{array}{c}\mathbf{6}^{\text {th }} \\
\text { month }\end{array}$ & $\begin{array}{c}\mathbf{1}^{\text {st }} \\
\text { year }\end{array}$ & $\begin{array}{c}\mathbf{2}^{\text {nd }} \\
\text { year }\end{array}$ \\
\hline $\begin{array}{c}\text { No } \\
\text { pain }\end{array}$ & No & 18 & 18 & 20 & 20 & 20 & 20 & 18 \\
& $\%$ & 90 & 90 & 100 & 100 & 100 & 100 & 90 \\
$\begin{array}{c}\text { Mild } \\
\text { pain }\end{array}$ & No & 2 & 2 & Nil & Nil & Nil & Nil & 2 \\
& $\%$ & 10 & 10 & Nil & Nil & Nil & Nil & 10
\end{tabular}

Friedman Test: Chi square=8.471 , d.f. $=6, p=0.206$ (NS); S=Significant, NS=Non -Significant

In regard to the second criterion, assessment of tooth mobility was as follows: In the first postoperative week, degree II mobility of tooth was recorded in 16 subjects ( $80 \%$ of cases) and degree I mobility in 4 subjects ( $20 \%$ of cases). In the second week, degree II mobility of tooth was recorded in 17 subjects (85\% of cases) and degree I mobility in 3 subjects (15\% of cases). In the first month visit, degree I mobility of tooth was recorded in 15 subjects (75\% of cases) and degree II mobility in 5 subjects ( $25 \%$ of cases). In the second ,sixth month and first year period, degree I mobility was recorded in 18 subjects (90\% of cases) and degree II mobility in 2 subjects ( $10 \%$ of cases). In the second year visit, degree I mobility was recorded also in 18 subjects ( $90 \%$ of cases) but with grade III mobility in two subjects $(10 \%$ of cases- lower right first molar teeth ).Statistical analysis showed a significant difference between the degree of tooth mobility and postoperative period intervals (Chi square $=83.580$, d.f. $=6, p=.000$. The results are shown in Table (2):

Table (2): Frequency and percentage of tooth mobility scores at scheduled visits.

\begin{tabular}{lcccccccc}
\hline $\begin{array}{c}\text { Tooth } \\
\text { mobility }\end{array}$ & $\begin{array}{c}\text { Frequency, } \\
\text { Percentage }\end{array}$ & $\begin{array}{c}\mathbf{1}^{\text {st }} \\
\text { week }\end{array}$ & $\begin{array}{c}\mathbf{2}^{\text {nd }} \\
\text { week }\end{array}$ & $\begin{array}{c}\mathbf{1}^{\text {st }} \\
\text { month }\end{array}$ & $\begin{array}{c}\mathbf{2}^{\text {nd }} \\
\text { month }\end{array}$ & $\begin{array}{c}\mathbf{6}^{\text {th }} \\
\text { month }\end{array}$ & $\begin{array}{c}\mathbf{1}^{\text {st }} \\
\text { year }\end{array}$ & $\begin{array}{c}\mathbf{2}^{\text {nd }} \\
\text { year }\end{array}$ \\
\hline \multirow{2}{*}{ Degree I } & No & 4 & 3 & 15 & 18 & 18 & 18 & 18 \\
& $\%$ & 20 & 15 & 75 & 90 & 90 & 90 & 90 \\
Degree II & No & 16 & 17 & 5 & 2 & 2 & 2 & \\
Degree & $\%$ & 18 & 85 & 25 & 10 & 10 & 10 & \\
III & No & & & & & & & 2 \\
\hline
\end{tabular}

Friedman Test: Chi square $=83.580$, d.f. $=6, p=.000$. (S) S=Significant, NS=Non - Significant

The third criterion to be evaluated was the presence or absence of sinus at the apical region of the tooth reimplanted. No clinical evidence of sinus formation was observed from the first week up to two years with exception of two cases ( lower right first molars) at the first and second year postoperative period. In the former case, the sinus was located at the region of the distal root while in the latter case, the sinus was clinically evident at the apical region of the mesiobuccal root. Statistical 
analysis revealed no significant difference between presence or absence of sinus
Chi square $=12.000$, d.f. $=6, p=0.062$ ). This is shown in Table (3).

Table (3): Frequency and percentage of presence or absence of sinus formation at scheduled visits.

\begin{tabular}{ccccccccc}
\hline Sinus & $\begin{array}{c}\text { Frequency }, \\
\text { Percentage }\end{array}$ & $\begin{array}{c}\mathbf{1}^{\text {st }} \\
\text { week }\end{array}$ & $\begin{array}{c}\mathbf{2}^{\text {nd }} \\
\text { week }\end{array}$ & $\begin{array}{c}\mathbf{1}^{\text {st }} \\
\text { month }\end{array}$ & $\begin{array}{c}\mathbf{2}^{\text {nd }} \\
\text { month }\end{array}$ & $\begin{array}{c}\mathbf{6}^{\text {th }} \\
\text { month }\end{array}$ & $\begin{array}{c}\mathbf{1}^{\text {st }} \\
\text { year }\end{array}$ & $\begin{array}{c}\mathbf{2}^{\text {nd }} \\
\text { year }\end{array}$ \\
\hline $\begin{array}{c}\text { Sinus } \\
\text { absent }\end{array}$ & No & 20 & 20 & 20 & 20 & 20 & 18 & 18 \\
& $\%$ & 100 & 100 & 100 & 100 & 100 & 90 & 90 \\
$\begin{array}{c}\text { Sinus } \\
\text { present }\end{array}$ & No & Nil & Nil & Nil & Nil & Nil & 2 & 2 \\
\hline
\end{tabular}

Friedman Test: Chi square $=12.000$, d.f. $=6, p=0.062$ (NS) ; S=Significant, NS=Non-Significant

The fourth criterion evaluated was radiographic assessment of periapical radiolucency (an example is shown in radiographs 1,2,3). Observations of the periapical radiograph at the first week, second week, first month and second month revealed the presence of periapical radiolucency but with reduction in size when comparison was made up to the second month interval. At the sixth month visit, twelve cases showed almost complete absence of radiolucency with bone formation around the amputated apical region of tooth, while eight cases showed small sized radiolucency still noticed. At the first and second year visits, periapical rarefaction was still evident in only two cases (lower right first molars ). Statistical analysis disclosed a significant difference between absence or presence of periapical radiolucency at interval visits ( Chi square $=77.013$, d.f. $=5, p=0.000$ ). This is shown in Table (4).

Table (4): Frequency and percentage of presence or absence of periapical radiolucency at scheduled visits.

\begin{tabular}{ccccccccc}
\hline $\begin{array}{c}\text { Periapical } \\
\text { radiolucency }\end{array}$ & $\begin{array}{c}\text { Frequency, } \\
\text { Percentage }\end{array}$ & $\begin{array}{c}\mathbf{1}^{\text {st }} \\
\text { week }\end{array}$ & $\begin{array}{c}\mathbf{2}^{\text {nd }} \\
\text { week }\end{array}$ & $\begin{array}{c}\mathbf{1}^{\text {st }} \\
\text { month }\end{array}$ & $\begin{array}{c}\mathbf{2}^{\text {nd }} \\
\text { month }\end{array}$ & $\begin{array}{c}\mathbf{6}^{\text {th }} \\
\text { month }\end{array}$ & $\begin{array}{c}\mathbf{1}^{\text {st }} \\
\text { year }\end{array}$ & $\begin{array}{c}\mathbf{2}^{\text {nd }} \\
\text { year }\end{array}$ \\
\hline PRESENT & No & 20 & 20 & 20 & 20 & 8 & 2 & 2 \\
& $\%$ & 100 & 100 & 100 & 100 & 40 & 10 & 10 \\
ABSENT & No & Nil & Nil & Nil & Nil & 12 & 18 & 18 \\
& $\%$ & Nil & Nil & Nil & Nil & 60 & 90 & 90 \\
\hline
\end{tabular}

Friedman Test: Chi square=77.013, d.f. $=5, p=0.000(\mathrm{~S}) ; \mathrm{S}=$ Significant, NS=Non - Significant

The fifth and sixth criterion (root resorption and ankylosis) were evaluated together. Observations were based on radiographic imaging (for both) with additional clinical examination of tooth by percussion (high metallic sound indicated ankylosis) . No evidence of root resorption and ankylosis was observed up to the sixth month. In the sixth month interval, root resorption with evident ankylosis was observed in five cases, two teeth with inflammatory root resorption with no ankylosis but apical rarefaction (lower right first molars which were removed at the end of study), while thirteen cases showed normal periodontal space around the root. Inflammatory root resorption was recorded in the same case with replacement 
resorption and ankylosis. This was also true for the following first and second year second year interval. Statistical analysis disclosed a significant difference between root resorption at interval visits ( $\mathrm{Chi}$ square $=35.000$, d.f. $=5, p=0.000)$ as well bony ankylosis (Chi square $=27.727$, d.f.=5, $p=0.000)$ This is shown in Table (5).

Table (5): Frequency and percentage of presence or absence of root resorption and ankylosis at scheduled visits.

\begin{tabular}{ccccccccc}
\hline $\begin{array}{c}\text { Root resorp- } \\
\text { tion } \\
\text { and Ankylo- } \\
\text { sis }\end{array}$ & $\begin{array}{c}\text { Frequency Per- } \\
\text { centage }\end{array}$ & $\begin{array}{c}\mathbf{1}^{\text {st }} \\
\text { week }\end{array}$ & $\begin{array}{c}\mathbf{2}^{\text {nd }} \\
\text { week }\end{array}$ & $\begin{array}{c}\mathbf{1}^{\text {st }} \\
\text { month }\end{array}$ & $\begin{array}{c}\mathbf{2}^{\text {nd }} \\
\text { month }\end{array}$ & $\begin{array}{c}\mathbf{6}^{\text {th }} \\
\text { month }\end{array}$ & $\begin{array}{c}\mathbf{1}^{\text {st }} \\
\text { year }\end{array}$ & $\begin{array}{c}\mathbf{2}^{\text {nd }} \\
\text { year }\end{array}$ \\
\hline PRESENT & No & NIL & NIL & NIL & NIL & $5+\left(2^{*}\right)$ & $\begin{array}{c}5+ \\
\left(2^{*}\right)\end{array}$ & $\begin{array}{c}5+ \\
(*)\end{array}$ \\
& $\%$ & NIL & NIL & NIL & NIL & 35 & 35 & 35 \\
ABSENT & No & 20 & 20 & 20 & 20 & 13 & 13 & 13 \\
& $\%$ & 100 & 100 & 100 & 100 & 65 & 65 & 65 \\
\hline
\end{tabular}

Friedman Test: ( Chi square $=35.000$, d.f. $=5, p=0.000)$ for root resorption (S); (Chi square=27.727, d.f. $=5, p=0.000)$ for ankylosis (S)

* Note: Two cases showed inflammatory root resorption with periapical radiolucency and no bony ankylosis. Only five cases showed replacement resorption with ankylosis.

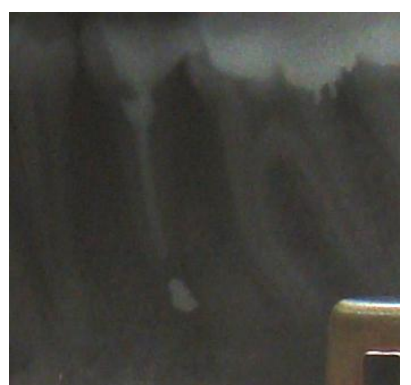

Radiograph 1; One week following surgery

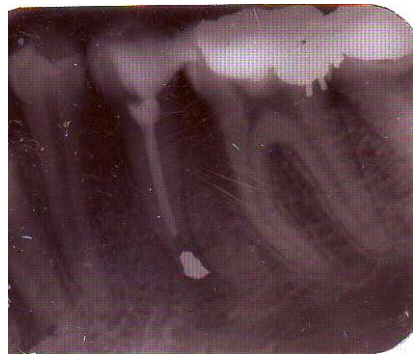

Radiograph 2; 1 month following surgery

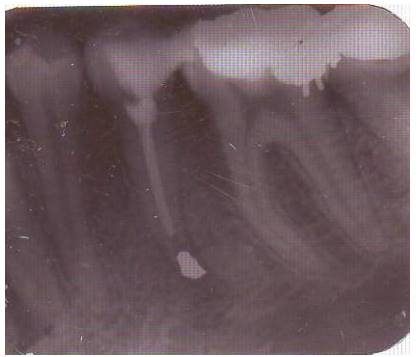

Radiograph 3; 6 month following surgery 


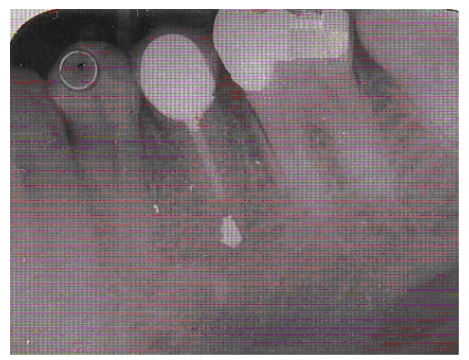

Radiograph 4; 1 years following surgery with post crown

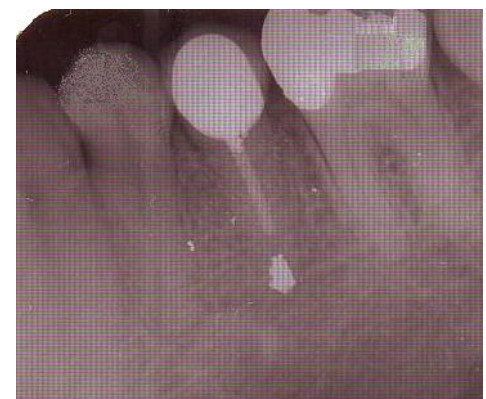

Radiograph 5; 2 years following surgery with post crown

\section{DISCUSSION}

Intentional replantation is a less invasive procedure compared to apical surgery. Periradicular surgery has its risk when there is proximity to anatomic structures like nerves, blood vessels, sinuses or adjacent roots. ${ }^{(11,12)}$ Also, the quality of root end preparation and retrofill in routine

periradicular surgery cannot exceed that of intentional replantation. In intentional replantation, there is good access to the tip of the root and root end preparation and filling are done better extraorally, thus achieving a better visual hermetic apical seal of the root canal system. This type of surgery requires considerable manipulation and is usually performed by oral surgeons or endodontic specialists and is considered an easy procedure that can be performed even by general practitioners. ${ }^{(13)}$ The duration and method of extraalveolar preservation and status of asepsis are critical parameters in preservation of cellular vitality of the periodontal ligament. ${ }^{(6,7,8)}$ In intentional replantation, these variables are controlled by performing all procedures under aseptic conditions and tooth should be reimplanted in a very brief period from the beginning to the end of the procedure ( about 15 minutes). The reduced extra-oral time of reimplanted tooth ( not more than 5 minutes) has great influence on maintaining the viability of the periodontal ligament. ${ }^{(3,4)}$ In the current study, the mean extra-alveolar duration was (2.15) minutes. Suture splinting was used to secure the stability of the reimplanted tooth because rigid splinting may harbor bacteria, delay healing and promote replacement resorption by not allowing physiological mobility. ${ }^{(13,14)}$ This was performed in the current trial. Patient hygiene plays a mandatory role in plaque control before and after surgery which in turn has great influences in success of the treatment. ${ }^{(14)}$ In the current study, scaling and polishing and chlorhexidine mouth wash before and after surgery was carried out. Following intentional replantation, there was marginal bone loss but less risk of causing bone dehiscence and of course no soft tissue injury or scars when compared with surgery because the osteogenic capacity of periosteum was reduced. ${ }^{(15)}$ In most cases of periradicular surgery, there is usually post operative discomfort such as pain and swelling while intentional replantation is usually uneventful. The lack of pain in this study is comparable with the literature. Most studies have reported little complaint of pain or discomfort. Any pain and swelling are most likely related to the extraction rather than the replantation portion of the procedure. Therefore the initial 
pain and swelling should not be confused with rejection. ${ }^{(14,16,17)}$ Replacement root resorption is a resorptive process that results in a replacement of the dental hard tissue by bone, hence the name. ${ }^{(18)}$ When a surface resorption stops, cells from the periodontal ligament will proliferate and populate the resorbed area. ${ }^{(19,20,21)}$ If the resorption is large it will take some time for the periodontal cells to cover the entire surface. Cells from nearby bone tissue may then arrive first and establish themselves on the resorbed surface. ${ }^{(22,23)}$ Bone is thus being formed directly upon the dental tissue. This results in a fusion between bone and tooth which is known as ankylosis. Replacement resorption and ankylosis are often used as synonyms. Ankylosis is a common finding following tooth replantation and the ankylosed teeth may remain for many years ${ }^{\left({ }^{(17)}\right.}$ Clinically, ankylosis is diagnosed by absent tooth mobility and by a percussion tone that is higher than in a normal tooth. ${ }^{(24,25)}$.. Several resources have reported the success rate of intentional replantation. The success rate of intentional replantation varies from $52 \%$ to $95 \%$, inversely related to the observation period and criteria of success. Bender and Rossman reported a success rate of $81 \%$ of 31 teeth followed for up to 22 years. ${ }^{(26,27)}$ Kingsbury and Weisenbaugh reported a success rate of $95 \%$ for 151 teeth followed for 3 years. ${ }^{(28)}$ The current trial showed around $80 \%$ success rate over a 2 year follow up. Several materials have been proposed in the litreture to improve the success of intentional replantation one of which is Emdogain (Enamel matrix derivative. ${ }^{(29)}$ The variability in postoperative follow-up and type of teeth replanted make it difficult to compare results with available studies conducted.

\section{CONCLUSION}

The success of intentional replantation is likely dependent upon a minimally traumatic extraction, short extra-oral time with copious irrigation and meticulous instrumentation as well as carefully controlled postoperative patient compliance. The clinical and radiographic results of cases in the current trial were satisfactory. Further study on a much more postoperative period( more than two years) and the use of Bio- materials to improve the success of intentional replantation is encouraged.

\section{REFRENCES}

1. Nuzzolese E, Ciruclli N, Lepore MM, DAmore A. Intentional dental replantation.J Contemp.Dent Prac. 2004; 5 (3): 16.

2. Bender IB, Rossman LE. Intentional replantation of endodontically treated teeth. Oral Surg Oral Med Oral Pathol. 1993;76(5):623-30.

3. Andreasen JO, Borum MK, Jacobsen HL, et.al. Replantation of 400 avulsed permanent incisors.4. Factors related to periodontal ligament healing. Endod Dent Traumatol.1995;11(2):76-89.

4. Chandra RV, Bhat KM. Twenty- year follow-up of an unconventional intentional replantation. J Can Dent Assoc 2006; 72(7): 639-642.

5. Peer M. Intentional replantation - a last resort treatment or a conventional treatment procedure?Nine case reports. Dent Tramatol 2004;20(1):48-55.

6. Demiralp B, Nohutcu RM, Tepe DI, Eratalay K. Intentional repalantation for periodontally involved hopeless teeth. Dent Traumatol 2003;19(1): 45-51.

7. Gutmann JL, Harrison JW. Surgical Endodontics. $1^{\text {st }}$ ed. All Indian Publisher and Distributor. India. 1999; Pp: 63-66, 154-162.

8. Marques MD, Moreira B, Eriksen HM. Prevalence of apical periodontitis and results of endodontic treatment in an adult portugese population. Int Endo $J$ 1998;31:161-165.

9. Cooper SA, Beaver WT. A model to evaluate mild analgesic in oral surgery out patients. Clin Pharmacol. Therap. 1976; 20: 241-250.

10. Lindhe J, Karring T, Lang NP. Clinical periodontology and implant dentistry.Black well publishing, Munksgaard, $4^{\text {th }}$ ed, 2003.Chap 12;390.

11. Dryden JA, Arens DE. Intentional replantation : a viable alternative for selected cases. Dent Clin North Am 1994;38:325353.

12. Kratchman S. Intentional replantation. Dent Clin North Am 1997;41:603-617.

13. Bender IB, Rossman LE: Intentional replantation of endodontitally treated 
teeth. Oral Surg Oral Med Oral Path, 1993; 76:623-629.

14. Guy SC, Goerlg AC: Intentional replantation: Technique and rationale. Quitessence Int 1984 ;5:595- 601.

15.Marx RE, Garg AK. Dental and craniofacial applications of platelet rich plasma. Quintessence publishing com, Inc, Illinois. ${ }^{\text {st }}$ ed 2005; Chap 4,89.

16.Boer de M, Raghoebar GM, Stegenga B, et al: Complications after mandibular third molar extraction. Quitessence Int .1995; 26:779.

17. Raghoebar GM, Vissink A .Results of Intentional Replantation of Molars J Oral Maxlllofac Surg. 1999: 57:240-244.

18.Andreasen JO. Relationship between surface and inflammatory resorption and changes in the pulp after replantation of permanent incisors in monkeys .J of Endo. 1981;7;294-301.

19. Lindskog S, Blomlof L, Hammarstrom L. Mitosis and micro-organisms in the periodontal membrane after storage in milk or saliva .Scand J Dent Res.1983a;91:456472.

20. Lindskog S, Blomlof L, Hammarstrom L. Repair of periodontal tissues in vivo and in vitro. J of Periodont . 1983b;10:188-205.

21.Lindskog S, Blomlof L, Hammarstrom L.Comparative effects of parathyroid hormone on osteoblasts and cementoblasts. $J$ Clin Periodont.1987;14:386-389.

22. Andreasen JO ,Kristersson L. Evaluation of different types of autotransplanted con- nective tissues as potential periodontal ligament substitutes. Int J of Oral Surg. 1981;10:189-201.

23. Gottlow J,Nyman S,Lindhe J, Karring T, Wennstom J. New attachment in the human peridontium by guided tissue regeneration :Case reports. $J$ of Clin Periodont.1986;13:604-616.

24.Andreasen JO. Periodontal healing after replantation of traumatically avulsed human teeth.Assesment by mobility testing and radiography. Acta Odonto Scand.1975; 24;263-286.

25. Andreasen JO. External root resorption :its implication in dental traumatology,paedodontics, periodontics, orthodontics and endodontics. Int $J$ of Endo.1985;8:109-118.

26. Cotter MR, Panzarino J. Intentional replantation: A case report. $J$ Endod 2006;32:579-582.

27. Bender IB, Rossman LE. Intentional replantation of endodontically treated teeth. Oral Surg Oral Med Oral Pathol 1993;76:623-30.

28.. Kingsbury BC Jr, Wiesenbaugh JM Jr. Intentional replantation of mandibular premolars and molars. J Am Dent Assoc 1971;83:1053-7.

29.Kenny DJ, Barret EJ, Johnston DH,Sigal MJ, Tenenbaum HC. Clinical management of avulsed permanent incisors using emdogain: initial report of an investigation. $J$ Can Dent Assoc 2000:66;1;21-25. 